\title{
Effect of the survival judgment task on memory performance in subclinically depressed people
}

\author{
Rui Nouchi ${ }^{1,2}$ * and Ryuta Kawashima ${ }^{1}$ \\ 1 Smart Ageing International Research Centre, Institute of Development, Aging and Cancer, Tohoku University, Sendai, Japan \\ 2 Japanese Society for the Promotion of Science, Tokyo, Japan
}

Edited by:

Carl Senior, Aston University, UK

Reviewed by:

Nathan Ridout, Aston University, UK Jonathan Nelson, Max-Planck Institute for Human Development, Germany

*Correspondence:

Rui Nouchi, Smart Ageing

International Research Centre,

Institute of Development, Aging \&

Cancer, Tohoku University, 4-1

Seiryo-cho, Aoba-ku, Sendai

980-8575, Japan

e-mail: rnouchi@idac.tohoku.ac.jp
Many reports have described that a survival judgment task that requires participants to judge words according to their relevance to a survival situation can engender better recall than that obtained in other judgment tasks such as semantic or self-judgment tasks. We investigated whether memory enhancement related to the survival judgment task is elicited or not in subclinically depressed participants. Based on the BDI score, participants were classified as either depressed or non-depressed participants. Then 20 depressed participants and 24 non-depressed participants performed a survival judgment task and an autobiographical recall task. Results showed memory enhancement related to the survival judgment task in both depressed and non-depressed participants, but showed lower memory enhancement related to the survival judgment task in depressed participants than in non-depressed participants. These results suggest that the survival judgment task benefit is a robust phenomenon. Moreover, that benefit was reduced by depressed emotion. The combination hypothesis better explains the mechanism of memory enhancement related to the survival judgment task than the functional, emotional, and arousal or congruency hypothesis does.

Keywords: depression, adaptive memory, survival judgment task, combination hypothesis, subclinical

\section{INTRODUCTION}

\section{DEPRESSED MOOD AND MEMORY PERFORMANCE}

Depressed mood can change a way we feel and can change our memory performance (Burt et al., 1995; Veiel, 1997). Three types of memory biases for depressed people have been frequently reported. A first memory bias is a mood congruent memory bias (e.g., Bower, 1981; Blaney, 1986). The mood congruent memory bias is that depressed participants have a tendency to recall negative emotional information, especially depression-relevant materials. A second memory bias is overgenerality of autobiographical memory (e.g., Williams et al., 2007). This bias is that depressed participants have a tendency to recall categories of repeated events or impair retrieval of memories of specific autobiographical events. A third memory bias is (general) memory deficits (e.g., Austin et al., 2001; Burt et al., 1995). For example, memory performance in depressed participants is worse than that in non-depressed participants. We focused on the memory deficits in this study. The reasons why we focused on memory deficit in depressed participants were (1) numerous studies reported the memory deficits in depressed people (e.g., Burt et al., 1995; Veiel, 1997; Austin et al., 2001), (2) some studies showed an association between severities of depressed mood and memory impairments (e.g., McDermott and Ebmeier, 2009; Sheline et al., 2006), (3) memory deficit would affects daily activity (e.g., memory deficits may cause forgetting to take medicine).

Many previous studies showed that depressed participants had memory deficits, especially episodic memory domain. Results of previous studies have shown that depressed participants show lower memory performance than non-depressed participants do in various memory tests with both verbal and visual stimuli (Austin et al., 2001; Fossati et al., 2002; Ilsley et al., 1995). Human memory performance can improve when we use effective encoding strategies such as a semantic judgment task (e.g., Does this word mean the same as XXX?; Craik and Lockhart, 1972) or a self-referent task (e.g., Does this word describe you?; Rogers et al., 1977). Even if using the semantic judgment task and the selfreferent judgment task, the memory performance of depressed participants has been shown to be lower than that of nondepressed participants (Breslow et al., 1981; Derry and Kuiper, 1981; Kuiper and Derry, 1982; Weingartner et al., 1981, 1982). Results of previous studies have shown that the semantic judgment task and the self-referent judgment task are facilitated by an elaboration process, which is the process of adding to the information (Craik and Tulving, 1975; Klein and Kihlstrom, 1986). Based on these results, depressed individuals were unable to conduct an elaboration process of a certain type (Williams et al., 1997). Consequently, memory performance in depressed participants is lower than that in non-depressed participants.

\section{SURVIVAL JUDGMENT TASK AND MEMORY PERFORMANCE}

Nairne et al. (2007) recently reported that the survival judgment task was the most effective encoding strategy. In the survival judgment task, participants were asked to judge whether or not the presented information was necessary for a survival situation. In this case, the participants were instructed to imagine a survival situation in which they were stranded in the grasslands of a foreign land with no basic survival materials. The memory performance of the survival judgment task was higher than that for either a 
semantic judgment task or a self-referent judgment task (Nairne et al., 2007, 2008). For example, Nairne et al. (2007) directly compared memory performance in the survival judgment task, a moving judgment task, a pleasantness judgment task, and a selfreferent judgment task. In the moving judgment task, participants judged whether or not the presented information was necessary for a moving situation. In the pleasantness judgment task, they judged whether or not the presented information was pleasant. In the self-reference judgment task, they were asked to judge how easily the word brings to mind an important personal experience. The result showed that the memory performance obtained through the survival judgment task was higher than that obtained using other judgment tasks.

Many researchers were able to replicate this memory enhancement by the survival judgment task (Kang et al., 2008; Nairne and Pandeirada, 2008; Nairne et al., 2008, 2009; Otgaar and Smeets, 2010; Otgaar et al., 2010; Weinstein et al., 2008). Results of the earlier studies suggested that the experimental design (withinsubjects or between-subjects; Nairne et al., 2007; Nairne and Pandeirada, 2008; Weinstein et al., 2008), the test conditions (free recall or recognition; Nairne et al., 2007, 2008; Kang et al., 2008), or a stimulus of some type (word or picture; Otgaar et al., 2010) does not influence this effect. Thus, the memory enhancement of the survival judgment task would be a robust memory phenomenon.

\section{EXPLANATORY HYPOTHESES FOR MEMORY ENHANCEMENT RELATED TO THE SURVIVAL JUDGMENT TASK}

There are some hypotheses which explain the memory enhancement of the survival judgment tasks. In this section, we focused on two main hypotheses (functional hypothesis and combination hypothesis). The benefit of the survival judgment task was mainly interpreted by a functional hypothesis. The functional hypothesis assumed that our memory was shaped and evolved to improve directly or indirectly the opportunity of survival (Jacob, 1977; Tooby and Cosmides, 1992, 2005; Nairne, 2005). Thus, our memory systems are biased or tuned to remember fitness (survival)-related information (Klein et al., 2002; Nairne, 2005). In this hypothesis, thinking a survival situation and judging presented information would improve the opportunity to survive. Therefore, memory performance in the survival judgment task is higher than that in the other tasks (e.g., pleasantness judgment task, self-referent judgment task, or moving judgment task; Nairne et al., 2007). This hypothesis assumed that thinking about the survival situation would tap into special cognitive adaptation or a kind of memory module which is specialized for remember and processing survival-related information (Nairne et al., 2007). The functional hypothesis explained that the memory enhancement of the survival judgment task would occur when participants think about the survival situation.

Recently, Nouchi (2011a,b) proposed a combination hypothesis that accounts for the benefit of the survival judgment task. The combination hypothesis is a combination of the functional perspective (Klein et al., 2002; Nairne, 2005) and elaboration perspective (Anderson and Reder, 1979). The combination hypothesis accepts the concept of the functional perspective of memory. Our human memory tends to remember fitness-related information
(Klein et al., 2002; Nairne, 2005). Moreover, our memory performance can be better when people conduct elaboration processes (Anderson and Reder, 1979). In this case, the elaboration is the process of adding to the information (e.g., a logical inference, an illustration or a detail image; Gagne, 1985). Memory performance is determined by the number and type of elaboration performed on the information (Anderson and Reder, 1979). Anderson and Reder (1979) reported that the elaboration capability is dependent on participants' experiences (aging) and abilities of other types (e.g., imagery ability). Nouchi (2011b) asserted that the number and type of elaboration would be facilitated during participants' consideration of whether or not the presented items might be useful in the survival situation. Thereby, imagining the survival situation would facilitate the conduct of the elaboration process, which would not occur in the other encoding tasks. The combination hypothesis assumed that the beneficial effect of the survival judgment task would only occur when participants conduct an adequate level of elaboration. The difference between the functional hypothesis and the combination hypothesis is whether to emphasize the elaboration process. The combination hypothesis emphasized the importance of the elaboration process to explain the memory enhancement of the survival judgment task.

\section{PURPOSE OF THIS STUDY AND PREDICTION OF RESULTS}

Although previous studies using the survival judgment task have provided strong evidence that the survival judgment task can improve memory performance (Kang et al., 2008; Nairne et al., 2008, 2009; Weinstein et al., 2008; Otgaar and Smeets, 2010; Otgaar et al., 2010; Nouchi, 2011a,b), all previous studies used only normal healthy participants. It remains unclear whether memory enhancement related to the survival judgment task occurs also for depressed participants, or not. Therefore, this study was designed to investigate exactly that question. The answer is critical for assessment of the robustness of the survival judgment task benefit. Results of our study are expected to improve our understanding of the mechanism of memory enhancement related to the survival judgment task.

Based on previous findings of memory enhancement related to the survival judgment task (Kang et al., 2008; Nairne et al., 2008, 2009; Weinstein et al., 2008; Otgaar and Smeets, 2010; Otgaar et al., 2010; Nouchi, 2011a,b) and results of previous studies of effective memory strategies for depressed participants (Breslow et al., 1981; Derry and Kuiper, 1981; Kuiper and Derry, 1982; Weingartner et al., 1981, 1982), we made two predictions. First, we predicted that the memory performance related to the survival judgment task in both non-depressed and depressed participants is higher than the memory performance on other tasks because information related to survival situations is expected to be important to humans independently of depressed conditions, because our memory system is expected to be tuned to adaptation (Klein et al., 2002; Nairne, 2005), and because memory enhancement related to the survival judgment task is expected to be a robust phenomenon (Nairne and Pandeirada, 2010). Secondly, we anticipated that the survival judgment task benefit in non-depressed participants is higher than that in depressed participants because previous studies have shown that an effective encoding strategy improved memory performance in depressed participants, but the 
memory performance of effective encoding strategy in depressed participants was actually lower than that in non-depressed participants (Breslow et al., 1981; Derry and Kuiper, 1981; Kuiper and Derry, 1982; Weingartner et al., 1981, 1982).

To investigate the memory benefit of the survival judgment task in depressed participants, we could also test whether the functional hypothesis or the combination hypothesis can account for the memory enhancement of the survival judgment task. If the functional hypothesis is correct, then only the first prediction would be confirmed. Because information about survival situations are important to humans independently of depressed mood, memory enhancement of the survival judgment task would occur in both depressed and non-depressed participants and there would be no differences of the benefit of the survival judgment tasks between depressed participants and non-depressed participants. If the combination hypothesis is correct, then both the first and second prediction would be confirmed. The reasons are that (1) the benefit of the survival judgment task was affected by the degree of elaboration process (Nouchi, 2011a,b) and (2) depressed people were unable to perform elaboration process of a certain kind (Breslow et al., 1981; Derry and Kuiper, 1981; Weingartner et al., 1981, 1982; Kuiper and Derry, 1982). Thus, the memory enhancement of the survival judgment task would occur in both depressed and non-depressed participants and the benefit of the survival judgment task in non-depressed participants would be higher than that in depressed participants.

This study would have some merits for both research fields of the memory enhancement of the survival judgment task and memory deficits in depression. First, we could examine the robustness of the memory enhancement of the survival judgment task. Second, we could test the explanatory hypotheses for the benefits of the survival judgment task. Third, we would give some implications about memory deficits in depressed people. Thus, we investigated whether or not the memory enhancements of the survival judgment task elicits using the subclinical depressed people. We discussed these issues in the discussion part.

\section{MATERIALS AND METHODS PARTICIPANTS AND DESIGN}

From the Tohoku University community, 114 undergraduate students (56 men, 58 women) were recruited and paid for their participation. One or two weeks before conducting an experiment (Time1), the 114 university students completed the Japanese version of the Beck Depression Inventory (BDI; Kojima et al., 2002), which is a 21-item self-report measure of depression. Based on results of previous studies (Hertel and Hardin, 1990; Ramponi et al., 2009), those who received a score of 10 or higher on the BDI were classified as subclinically depressed participants; those with the BDI scores of 9 or lower were regarded as non-depressed participants. This criterion was based on the BDI manual (Beck and Beamesderfer, 1974; Kendall et al., 1987). Many previous studies used the same criterion (e.g., Hertel and Hardin, 1990; Ramponi et al., 2009, 2010). A lower cutoff is appropriate when the aim is to maximize the detection of depression (Brantley et al., 2000). Next, we contacted these participants by e-mail or phone and asked these participants whether or not they could participate in our experiment. Finally, 44 participants participated in the study (20 depressed participants and 24 non-depressed participants). The 44 participants answered the BDI again on the day of the experiment (Time 2). A correlation of the BDI score between Time1 and Time 2 was 0.92 . Table 1 presents the profiles of the two groups. IQ was assessed using the Japanese Adult Reading Test - 25 word version (JART-25; Matsuoka et al., 2006). JART-25 is a reading test consisting of 25 Kanji compound words (e.g., 親父, 煙草). In this test, participants were asked to read each Kanji compound word aloud. This task assesses reading ability and IQ. The two groups were matched for age and the JART score. All participants denied past diagnosis or treatment of any neurological or psychiatric disorder. Participants were informed about relevant ethical considerations before entering the study, and written informed consent was obtained from each. The protocol of this study and informed consent procedures were approved by the Ethics Committee of the Tohoku University Graduate School of Medicine. This study was conducted in accordance with the ethical code of the Japanese Psychological Society. The mean age of these participants was 20.37 years $(\mathrm{SD}=1.60)$.

A 2 (depression: non-depressed mood and subclinical depressed mood) $\times 2$ (task: survival and autobiographical) factor design was used. The first factor was between-subjects design. The second factor was within-subjects design.

\section{MATERIAL}

From a list of Japanese nouns (Ogawa and Inamura, 1974), 36 nouns were selected. The nouns were written in two Chinese characters. The imagery values (7 points scale; from 1: very low to 7 : very high) and the concreteness values ( 7 points scale; from 1: very low to 7: very high) of these words were both greater than 5.0. Thus, our materials had high imagery and concreteness values. The 36 words were divided into two lists of 18 words (list A and list B; see Table A1 in Appendix). These lists had equivalent imagery (list $A=6.11$, list $B=6.11$ ), concreteness (list $A=6.07$, list $B=6.19$ ), meaningfulness (list $A=3.93$, list $B=4.05 ; 7$ points scale; from 1: very low to 7: very high), and ease of learning (list $A=4.72$, list $\mathrm{B}=4.79 ; 7$ points scale; from 1 : very difficult to 7 : very easy). Half of the participants were presented with list A for the survival

Table 1 | Mean participant characteristics.

\begin{tabular}{|c|c|c|c|c|c|c|}
\hline & \multirow{2}{*}{\multicolumn{2}{|c|}{$\begin{array}{l}\text { Non-depressed } \\
\text { participants } \\
(11 \mathrm{M} / 13 \mathrm{~F})\end{array}$}} & \multirow{2}{*}{\multicolumn{2}{|c|}{$\begin{array}{l}\begin{array}{l}\text { Depressed } \\
\text { participants }\end{array} \\
(9 M / 11 F)\end{array}$}} & \multirow[t]{3}{*}{$\begin{array}{l}\text { Effect } \\
\text { size }(d)\end{array}$} & \multirow[t]{3}{*}{$p$-value } \\
\hline & & & & & & \\
\hline & Mean & SD & Mean & SD & & \\
\hline Age (year) & 20.88 & 0.95 & 20.55 & 1.05 & 0.33 & 0.90 \\
\hline JART (score) & 20.13 & 3.49 & 20.00 & 3.28 & 0.04 & 0.66 \\
\hline BDITime1 (score) & 3.25 & 2.11 & 15.65 & 2.03 & 5.97 & 0.00 \\
\hline BDITime2 (score) & 3 & 1.84 & 14.8 & 2.61 & 5.32 & 0.00 \\
\hline
\end{tabular}

M, Male; F, Female; SD, standard deviation; JART, Japanese Adult Reading Test 25; BDI, Beck Depression Inventory, BDI was measured 1 or 2 weeks before conducting the experiment (BDI Time1) and on the day of the experiment (BDI Time2). 
judgment task and list B for the autobiographical recall task; the other half were presented with list A for the autobiographical recall task and list $\mathrm{B}$ for the survival judgment task.

\section{ORIENTATION TASKS AND INSTRUCTIONS}

We used the survival judgment task and the autobiographical recall task at an encoding phase. There were some reasons why we selected the autobiographical recall task. Firstly, many previous studies used the autobiographical recall task as a comparative task (e.g., Nairne et al., 2007; Nouchi, 2011a,b). Secondly, the autobiographical recall task was one of effective encoding task (e.g., Rogers et al., 1977). Thirdly, we would like to avoid to any confusion in conducting the encoding tasks, because we used a within-subject design and trials of the survival judgment task and the autobiographical recall task were presented in a random order. These procedures might confuse participant to conduct the encoding task if we used similar tasks (e.g., survival and moving judgment task). Thus, we selected the survival judgment and the autobiographical recall tasks. These tasks resembled those explained by Nouchi (2011a). Participants were told the following scenarios.

In the survival judgment task, they were told, "We would like you to imagine that you are stranded in the grasslands of a foreign land, with no basic survival materials. Over the next few months, you'll need to find steady supplies of food and water and protect yourself from predators. We are going to show you a list of words. Then we would like you to rate how relevant each word would be for you in this survival situation. Some words might be relevant and others might not be - it's up to you to decide." The participants rated these words using a five-point scale ranging from 1 (completely irrelevant) to 5 (extremely relevant).

In the autobiographical recall task, they were told, "We would like you to think of personal experiences you have had in your life. We will present you with a series of words, and for each word we would like you to rate how easily the word brings to mind an important personal experience." The participants rated these words using a five-point scale ranging from 1 (very difficult) to 5 (very easy).

\section{PROCEDURES}

This experiment was in an incidental memory situation. It was conducted in an experimental room. Participants were told a cover story explaining that the aim of this study was to investigate language ability. First, participants signed an informed consent form. Then participants were given instructions for the survival judgment task and autobiographical recall task. After the instructions, they practiced these judgment tasks three times. Then participants performed both the survival judgment task and the autobiographical recall task. Each trial began with the presentation of instructions (survival or self) for $1.5 \mathrm{~s}$ in the center of a screen, followed by a fixation cross for $1 \mathrm{~s}$ in the center of the screen; then stimulus for $4 \mathrm{~s}$ in the center of the screen. Participants were asked to rate the stimulus by pressing the keyboard. The sizes of instructions and stimulus were about $20 \mathrm{~mm} \times 20 \mathrm{~mm}$ per character on the display. In all, 36 words were presented, with 18 nouns assigned to each of the two judgment tasks (survival and autobiographical). Two counterbalanced orderings enabled assignment of the words to each condition across participants. Trials of the survival judgment task and the autobiographical recall task were presented in a random order that was unique for each participant. After participants judged all of 36 words, participants performed a filler task. They were asked to perform simple mathematical calculations for $2 \mathrm{~min}$. After the filler task, participants were asked to write down as many words as they could remember from 36 words presented under the survival judgment task and the autobiographical recall tasks in the encoding phase. Five minutes were given for this recall task. Finally, participants were asked to rate arousal and emotional valence of the survival judgment task and the autobiographical recall task. Participants rated the tasks using a nine-point scale (for arousal scale, $1=$ excited and $9=$ calm; for emotional valence scale, $1=$ happy and $9=$ sad). Participants were instructed to "please rate your feeling during you have conducted the survival judgment tasks and the autobiographical recall task." We collected ratings of arousal and emotional valence in the survival judgment task. The autobiographical recall task was used to examine whether differences of ratings of these tasks would affect memory enhancement related to the survival judgment task or not. Some earlier results of studies suggested that the difference of the arousal rating might enhance the memory performance of the survival judgment task.

\section{RESULTS}

\section{MEMORY PERFORMANCE}

The means of the proportions of recall are presented in Table 2. The proportion of recall was analyzed using a 2 (depressed mood: non-depressed and depressed) $\times 2$ (task: survival and autobiographical) mixed ANOVA with depressed mood as the betweensubjects factor and task as the within-subjects factor. The analysis revealed the main effect of depressed mood, $F(1,42)=24.56$, $\eta_{p}^{2}=0.37, p<0.001$, the main effect of task, $F(1,42)=172.43$, $\eta_{p}^{2}=0.80, p<0.001$, and the significant interaction for depressed mood $\times$ task, $F(1,42)=4.20, \eta_{p}^{2}=0.09, p<0.05$. The test of simple main effects of interaction for depressed mood $\times$ task showed that the non-depressed participants better recalled those words judged in both the survival judgment task and autobiographical recall task than the depressed participants did, $F(1,42)=24.40$, $\eta_{p}^{2}=0.37, p<0.001$, and $F(1,42)=6.21, \eta_{p}^{2}=0.13, p<0.05$. These results suggest that the memory performance of the nondepressed participants was better than that of the depressed participants. The non-depressed participants better recalled those words judged in the survival situation than the words judged in the autobiographical recall task, $F(1,23)=155.11, \eta_{p}^{2}=0.87, p<0.001$. Moreover, the depressed participants better recalled those words judged in the survival situation than the words judged in the autobiographical recall task, $F(1,23)=46.08, \eta_{p}^{2}=0.71, p<0.001$. These results revealed that the survival judgment task benefit occurred in both non-depression participants and depression participants.

We also conducted Pearson's correlation analyses between the proportions of recall and the BDI scores in each task. The result showed that the correlation between the proportions of recall in the survival judgment task and the BDI scores was -0.57 and the correlation between the proportions of recall in the autobiographical recall task and the BDI scores was -0.35 . These results showed that depressed mood reduced memory performance in the 
Table 2 | Mean proportion of recall, reaction times and ratings score in non-depressed and depressed participants.

\begin{tabular}{|c|c|c|c|c|c|c|c|c|c|c|c|}
\hline \multirow[t]{2}{*}{ Task } & & \multicolumn{2}{|c|}{ Proportion recall } & \multicolumn{2}{|c|}{ Reaction times (ms) } & \multicolumn{2}{|c|}{ Rating score } & \multicolumn{2}{|c|}{ Arousal score } & \multicolumn{2}{|c|}{ Emotional valence score } \\
\hline & & Survival & Auto & Survival & Auto & Survival & Auto & Survival & Auto & Survival & Auto \\
\hline \multirow[t]{2}{*}{ Non-depressed participants } & $M$ & 0.61 & 0.35 & 2017.79 & 1962.86 & 3.70 & 3.93 & 5.46 & 5.73 & 4.97 & 5.19 \\
\hline & SD & 0.08 & 0.08 & 308.41 & 319.73 & 0.93 & 1.02 & 1.44 & 1.44 & 1.49 & 1.29 \\
\hline \multirow[t]{2}{*}{ Depressed participants } & $M$ & 0.48 & 0.29 & 2013.89 & 2019.80 & 3.72 & 3.95 & 5.45 & 5.17 & 5.08 & 5.25 \\
\hline & SD & 0.09 & 0.08 & 273.76 & 310.18 & 0.86 & 0.95 & 1.11 & 1.25 & 1.37 & 1.27 \\
\hline
\end{tabular}

Survival, survival judgment task; Auto, autobiographical recall task; $M$, mean; SD, standard deviation.

survival judgment and autobiographical recall tasks. These results indicated that a degree of depressed mood was related to memory performance.

\section{ENHANCED SCORE OF THE SURVIVAL JUDGMENT TASK}

We simply calculated the enhanced score of the survival judgment task (the memory performance of the survival judgment task minus the memory performance of the autobiographical recall task). In that calculation, we used the memory performance of the autobiographical recall task to represent the baseline performance (Nouchi, 2011a,b). Because the memory performance of the autobiographical recall task was different between the nondepressed participants and the depressed participants, we conducted an analysis of covariance (ANCOVA) for the enhanced scores. The enhanced scores were the dependent variable; groups (non-depressed, depressed) constituted the independent variable. The memory performance of the autobiographical recall task was the covariate to exclude the possibility that the difference in the memory performance of autobiographical recall task (baseline performance) between groups affected the result. The ANCOVA results showed that the enhanced score of the non-depressed participants $(M=0.26, \mathrm{SD}=0.10)$ was higher than that of the depressed participants $(M=0.18, \mathrm{SD}=0.12), F(1,41)=16.51$, $\eta_{p}^{2}=0.45, p<0.001$. The result suggested that memory enhancement related to the survival judgment task in the non-depressed participants was higher than that in the depressed participants.

Based on previous studies that investigated the effects of rating scores on memory enhancement related to the survival judgment task (Kroneisen and Erdfelder, 2011), we analyzed correlations between rating scores and memory performance in all four conditions (non-depression - survival, depression - survival, non-depression - autobiographical, and depression - autobiographical). We found no significant correlation in any condition: non-depression - survival $(r=-0.12$, n.s. $)$, depression - survival $(r=-0.13$, n.s. $)$, non-depression - autobiographical $(r=-0.15$, n.s.), and depression - autobiographical $(r=-0.14$, n.s. $)$.

\section{RATINGS AND REACTION TIMES}

We analyzed the rating scores and reaction times under the survival judgment and the autobiographical recall tasks. Table 2 presents the mean ratings score and the mean reaction times. Rating scores were analyzed using a 2 (depressed mood: nondepressed and depressed) $\times 2$ (task: survival and autobiographical) mixed ANOVA with depressed mood as the between-subjects factor and task as the within-subjects factor. Results showed no significant differences for the main effect of depressed mood, $F(1,42)=0.02, \eta_{p}^{2}=0.00$, n.s., for the main effect of task, $F(1$, $42)=1.44, \eta_{p}^{2}=0.01$, n.s., or for the significant interaction for depressed mood $\times$ task, $F(1,42)=0.00, \eta_{p}^{2}=0.00$, n.s.

Reaction times were also analyzed using a 2 (depressed mood: non-depressed and depressed) $\times 2$ (task: survival and autobiographical) mixed ANOVA with depressed mood as the betweensubjects factor and task as the within-subjects factor. The results showed no significant differences for the main effect of depressed mood, $F(1,42)=0.13, \eta_{p}^{2}=0.00$, n.s., for the main effect of task, $F(1,42)=0.19, \eta_{p}^{2}=0.00$, n.s., or for the significant interaction for depressed mood $\times$ task, $F(1,42)=0.29, \eta_{p}^{2}=0.01$, n.s.

Finally, arousal and emotional valence scores for tasks were analyzed separately using a 2 (depressed mood: non-depressed and depressed mood) $\times 2$ (task: survival and autobiographical) mixed ANOVA with depressed mood as the between-subjects factor and task as the within-subjects factor. These results showed no significant differences for the main effect of the depressed mood [arousal; $F(1,42)=0.92, \eta_{p}^{2}=0.01$, n.s., emotional; $F(1,42)=0.09, \eta_{p}^{2}=0.00$, n.s.], the main effect of the task [arousal; $F(1,42)=0.00, \eta_{p}^{2}=0.00$, n.s., emotional; $F(1$, $42)=0.47, \eta_{p}^{2}=0.00$, n.s.], or the interaction for depressed mood and task [arousal; $F(1,42)=1.03, \eta_{p}^{2}=0.01$, n.s., emotional; $F(1$, 42) $=0.00, \eta_{p}^{2}=0.00$, n.s. $]$.

\section{DISCUSSION}

This study was designed to examine whether or not memory enhancement related to the survival judgment task could be elicited in depressed participants. This study confirmed our two predictions. First, the memory performance of the survival judgment task in non-depressed and depressed participants was higher than that of the autobiographical recall task in non-depressed and depressed participants. The first finding can be explained by the functional perspective. Our memory system might be tuned to remember fitness-related information (Klein et al., 2002; Nairne, 2005), then information related to survival situations would be important for all people. For this reason, memory enhancement related to the survival judgment task was elicited in both nondepressed and depressed participants. The first findings suggest that memory enhancement related to the survival judgment task is a robust phenomenon irrespective of a depressed mood.

Second, memory enhancement related to the survival judgment task in depressed participants is expected to be lower than 
that in non-depressed participants. The second findings can be accounted for by the elaboration perspective. Memory performance is expected to be determined by the degree of elaboration performed on the information (Anderson and Reder, 1979). Results of previous studies have shown that the degree of elaboration in depressed participants was lower than that in nondepressed participants (Breslow et al., 1981; Derry and Kuiper, 1981; Weingartner et al., 1981, 1982; Kuiper and Derry, 1982). Moreover, some previous studies of memory enhancement related to the survival judgment task showed that the degree of elaboration process affects memory performance of the survival judgment task (Kroneisen and Erdfelder, 2011; Nouchi, 2011a). For example, Kroneisen and Erdfelder (2011) used an original survival scenario (Nairne et al., 2007) and a short survival scenario. The difference between the original survival scenario and the short survival scenario was the number of problems related to the survival situation. The original survival scenario includes three main survival problems (no food, no water, and predators). However, the short survival scenario presents a problem (no water). The original scenario was expected to facilitate more elaborate processing than the short scenario. Kroneisen and Erdfelder (2011) demonstrated that the survival judgment task benefit in the original scenario was greater than that in the short scenario. This result suggested that the degree of the elaboration process influences the memory performance of the survival judgment tasks. Presumably, memory enhancement related to the survival judgment task in the depressed participants was less than that in the non-depressed participants because the degree of elaboration process in depressed participants was lower than that in non-depressed participants. The second finding suggests that memory enhancement related to the survival judgment task is influenced by the participant's depressed mood.

\section{DISCUSSION OF AN EXPLANATORY HYPOTHESIS FOR MEMORY ENHANCEMENT RELATED TO THE SURVIVAL JUDGMENT TASK}

Our results demonstrated that (1) the survival judgment task led to improve memory performance in both the depressed and non-depressed participants and (2) the benefit of the survival judgment tasks in non-depressed participants was higher than that in depressed participants. These results clearly supported the combination hypothesis (Nouchi, 2011a,b). Some explanatory hypotheses which explain the memory enhancement of the survival judgment task have been proposed (e.g., functional hypothesis, congruent hypothesis, emotional and arousal hypothesis, combination hypothesis). In the next section, we consider which explanation hypothesis can explain memory enhancement related to the survival judgment task.

\section{The functional hypothesis}

The survival judgment task benefit was interpreted mainly by the functional hypothesis, which has an evolutional perspective of memory (Nairne et al., 2007). Evolutionary psychologists (Tooby and Cosmides, 1992, 2005) have proposed that our cognitive processes have been shaped by adaptation. Following that reasoning, the functional perspective assumed that our memory systems are biased or tuned to remember fitness (survival)-related information (Klein et al., 2002; Nairne, 2005). In the survival judgment task, participants were asked to think about or imagine a survival situation and then judge whether or not the presented information would be useful in the survival situation. Thinking about a survival situation and judging the presented information would improve their probability of survival. Therefore, memory performance in the survival judgment task is higher than that in other tasks (e.g., pleasantness judgment task, self-referent judgment task, and moving judgment task). Although the functional perspective of memory enhancement related to the survival judgment task is widely accepted (Nairne and Pandeirada, 2010, 2011), the functional perspective was unable to explain our results. Based on the functional hypothesis, the survival judgment task benefit in the non-depressed participants would be equal to that in the depressed participants because information related to survival situations is important for survival of both non-depressed and depressed participants. The functional hypothesis might explain our first prediction: that the survival judgment task benefit occurs in both depressed and non-depressed participants. However, it would not explain our second hypothesis: that the survival judgment task benefit in non-depressed participants is better than that in depressed participants.

\section{The congruent hypothesis}

A second possible explanatory hypothesis is a congruent hypothesis. The congruent hypothesis is that participants would show better memory for items which are rated with high rating scores during encoding tasks than items which are rated with low rating scores. In the case of the survival judgment task, a high rating score means that items are rated relevant to a survival situation. Some items in the survival judgment task might be assigned higher rating scores than in other judgment tasks; then the memory performance of the survival judgment task would be better than that of other judgment tasks. Some previous studies might be explained by the congruent hypothesis (Butler et al., 2009), but the congruent hypothesis could not account for our result. In our study, no significant differences of the rating scores were found between those of encoding tasks (survival and self-judgment tasks) and groups (non-depressed and depressed participants). Moreover, no significant differences of correlations were found between the rating scores and memory performance in any condition. Consequently, only the congruent hypothesis was unable to explain memory enhancement related to the survival judgment task.

\section{The emotional and arousal hypothesis}

Thirdly, some researchers (Nairne et al., 2007; Weinstein et al., 2008) have proposed an emotional and arousal hypothesis to account for the survival judgment task benefit. The emotional and arousal hypothesis is based on evidence that emotion can enhance memory performance (LaBar and Cabeza, 2006). The emotional and arousal hypothesis implies that the survival judgment task can evoke greater emotion and arousal than other control tasks; for that reason, the memory performance in the survival judgment task would be higher than that in other control tasks. We investigated this possibility of analyzing arousal and emotional valence ratings of encoding tasks (survival and self). Results show no significant differences between the encoding tasks in terms of the arousal and valence emotional ratings. The same results were 
reported also by Soderstrom and McCabe (2011). For these reasons, the emotional and arousal hypothesis was unable to account for memory enhancement related to the survival judgment task.

\section{The combination hypothesis}

A final explanatory hypothesis is a combination hypothesis. Nouchi (2011a) recently proposed the combination hypothesis that accounts for the survival judgment task benefit. The combination hypothesis is a combination of the functional perspective (Klein et al., 2002; Nairne, 2005) and the elaboration perspective (Anderson and Reder, 1979). The combination hypothesis accepts the concept of the functional perspective of memory. Evolutionary psychologists (Tooby and Cosmides, 1992,2005) proposed that our cognitive processes have been shaped by adaptation. Following that reasoning, the functional perspective assumed that our memory systems are biased or tuned to remember fitness-related information (Klein et al., 2002; Nairne, 2005). Therefore, imagining a survival situation would support better retention than imagining other situations that are unrelated to survival (e.g., moving) or conducting other tasks (e.g., self, semantic, and pleasantness). Moreover, our memory performance can be better when we conduct an elaboration process of some kind (Anderson and Reder, 1979). The elaboration means the process of adding information (e.g., a logical inference, an illustration, or a detailed image; Gagne, 1985) to the stimulus. Memory performance is expected to be determined by the number and type of elaboration performed on the information (Anderson and Reder, 1979). Nouchi (2011b) asserted that the number and type of elaboration is facilitated during a participant's consideration of whether or not the presented items might be useful in the survival situation. Thereby, imagining the survival situation would engender conduct of more elaboration processes than other encoding tasks would. The combination hypothesis assumed that the beneficial effect of the survival judgment task would occur only when participants conduct an adequate level of elaboration. Supporting the combination hypothesis, Kroneisen and Erdfelder (2011) reported that a degree of elaboration affected memory enhancement related to the survival judgment task. Anderson and Reder (1979) also reported that the elaboration capability is dependent on a participant's experiences (aging) and abilities (e.g., imagery ability). For example, the amount of the elaboration in elderly people was lower than that in younger people (Eysenck, 1974; Erber et al., 1980; Daselaar et al., 2003). Consistent with the combination hypothesis, Nouchi (2011b) demonstrated that memory enhancement related to the survival judgment task in elderly participants was lower than that in younger participants. The combination hypothesis might be a generally versatile explanation for memory enhancement related to the survival judgment task because the combination hypothesis has both adaptive and elaboration perspectives. Based on the combination hypothesis, our results can be explained as follows. In the survival judgment task, participants are asked to imagine the survival situation and judge whether or not the presented item is necessary in the survival situation. Presumably, considering whether or not the presented items might be used in the survival situation would promote various elaboration processes. For example, participants would think about the meaning of the presented items, recall past episodes in which they used the presented items, and imagine future episodes in which they would use the presented item in a survival situation. Consequently, compared to the autobiographical recall task, the survival judgment task could be expected to facilitate the elaboration process that engenders more connections between the target item and other information in memory. Therefore, the memory performance in the survival judgment task might be higher than that in other tasks. Additionally, the elaboration process is expected to be reduced by depressed mood (Breslow et al., 1981; Derry and Kuiper, 1981; Weingartner et al., 1981, 1982; Kuiper and Derry, 1982). For those reasons, memory enhancement related to the survival judgment task in depressed participants is expected to be lower than that in non-depressed participants.

We discussed the functional hypothesis, the congruent hypothesis, the emotional and arousal hypothesis, and the combination hypothesis above. The combination hypothesis could be expected to expound memory enhancement related to the survival judgment task sufficiently compared to the other hypotheses. Hypotheses of memory enhancement related to the survival judgment tasks have emphasized either a basic perspective of memory or a functional perspective of memory. The basic perspective of memory can explain phenomena related to memory such as memory enhancement related to the survival judgment task using basic memory principles (e.g., elaboration or arousal). The functional perspective of memory assumes that our memory is shaped and that it evolved because it improves the probability of survival either directly or indirectly (Tooby and Cosmides, 1992, 2005; Nairne, 2005). For instance, the congruent hypothesis (Butler et al., 2009) and the emotional and arousal hypothesis (Nairne et al., 2007; Weinstein et al., 2008) are based on the basic perspective of memory. However, the functional hypothesis specifically examines functions of memory (Nairne et al., 2007). The combination hypothesis has the basic perspective (elaboration) of memory and the functional perspective of memory. Therefore, the combination hypothesis can explain memory enhancement related to the survival judgment task better than other hypotheses. Presumably, memory researchers would consider memory phenomena using the basic and functional perspectives. Memory enhancement related to the survival judgment task can serve as a starting point for thinking about the basic and the functional perspectives of memory. The experimental paradigm of the survival judgment task is basic, including concepts such as paradigms of levels of processing (Craik and Tulving, 1975) and self-referent tasks (Rogers et al., 1977). Therefore, many memory researchers can easily start to investigate memory enhancement related to the survival judgment task.

\section{FUTURE STUDIES AND LIMITATIONS}

Although our study showed that memory enhancement related to the survival judgment tasks can be elicited independently of the depressed emotion, some questions remain unanswered. First, it remains unclear whether or not memory enhancement related to the survival judgment task would occur in other negative (e.g., anxiety) or positive (e.g., happy) emotional states. Second, it is important to examine whether or not an emotional valence of stimulus (e.g., positive emotional stimulus or negative emotional stimulus) can affect memory enhancement related to the survival judgment task in depressed people. Although depressed 
people tend to recall negative emotional stimuli compared to positive emotional stimuli (Bradley and Mathews, 1988; Ramel et al., 2007), the effects of the emotional valence on memory enhancement related to the survival judgment task remain unclear in depressed people. Further research is necessary to test the effect of emotional states and emotional valence of stimulus on memory enhancement related to the survival judgment task. Our results should be regarded as first steps toward understanding the effect of emotion on memory enhancement related to the survival judgment task.

Our methods in this study had some limitations. A first limitation is a classification of participants. To divide participants into depressed participants and non-depressed participants, we used the $9 / 10$ cutoff score on the BDI. The reasons why we used this cutoff score were that (1) previous studies in memory research fields used this 9/10 cutoff score (e.g., Hertel and Hardin, 1990; Ramponi et al., 2009, 2010) and (2) Beck who developed the BDI recommended to use $9 / 10$ cutoff score (Beck and Beamesderfer, 1974). Although the $9 / 10$ cutoff score is one of standard methods in the BDI, using a cutoff score method have a limitation. If there are a participant scoring 9 on the BDI and a participant scoring 10 on the BDI, the participant scoring 9 would be allocated to a non-depressed participants group and the participants scoring 10 would be allocated to a depressed participants group even if the difference of the participants is only one point difference on the BDI. Further research should combine use of the BDI and other depression measures to divide participants into depressed or non-depressed participants groups. A second limitation is a method to measure arousal and emotional valences. We asked participants to rate arousal and emotional valences of the two encoding tasks. This method only measured the overall ratings of arousal and emotional valences for two tasks. There is a possibility that arousal and emotion valences on each word or item might affect the memory enhancement of the survival judgment task. Presumably, a superior method would be that participants rate the arousal and emotion valence of all presented words after the experiment. Further study should use a better method which could investigate the effects of arousal and emotional valence of the item level on the memory enhancement of the survival judgment task. Finally, we examined subclinically depressed participants. It remains unclear whether memory enhancement related to the survival judgment task would occur in clinically depressed participants. Future studies should examine clinically depressed participants.

\section{IMPLICATIONS FOR MEMORY DEFICITS IN DEPRESSED PEOPLE}

Memory deficits in depressed people are one of main cognitive impairments in depressed people (e.g., Burt et al., 1995). The memory deficits could be explained by the initiative deficit model (Hertel and Hardin, 1990; Hertel, 1994, 1998) or the resource allocation model (Ellis and Ashbrook, 1988; Ellis et al., 1997). The initiative deficit model (Hertel and Hardin, 1990; Hertel, 1994, 1998) hypothesized that depressed mood would reduce the initiative to use beneficial strategies in memory tasks. Thus, memory performance in depressed participants would be lower than that in non-depressed participants. On the other hand, the resource allocation model (Ellis and Ashbrook, 1988; Ellis et al., 1997) explains memory deficits by limited cognitive capacities. In this model, depressed people would have tendencies to focus on irrelevant task features or to think more about their own mood states. Because these tendencies may lead to reduce cognitive capacities in depressed people, memory performance in depressed people would be lower than that in non-depressed people.

Our results showed that memory performance in depressed participants was lower than that in non-depressed participants, even if depressed participants used effective encoding strategies or tasks (survival judgment and autobiographical recall tasks). This result supported the resource allocation model. Memory deficits in depressed people could be explained as follows. Presumably, depressed people may be disturbed by irrelevant thoughts (e.g., focusing on irrelevant task features) during conducting effective encoding tasks (survival judgment or autobiographical recall tasks). Because cognitive capacities in depressed people would be limited by these irrelevant thoughts, they could not conduct an elaboration process of a certain type (Williams et al., 1997). Therefore, memory performance in depressed people would be lower compared to non-depressed people.

Based on the resource allocation model, it would be important to reduce task irrelevant thoughts as well as to use effective encoding strategies for improvement of memory performance in depressed people. For example, Hertel and Rude (1991) showed that focused attention and inhibition of task irrelevant thoughts could improve memory performance in depressed people. In order to improve memory performance in depressed people, both using effective encoding strategies and reducing task irrelevant thoughts may be necessary. Further studies which use both approaches to reduce task irrelevant thoughts and to use effective encoding strategies should be needed in order to clarify the mechanism of memory deficits in depression and to propose techniques to improve memory performance in depressed people.

\section{CONCLUSION}

In summary, our study was the first to show evidence of memory enhancement related to the survival judgment task in depressed participants. This result reflects that memory enhancement related to the survival judgment task is a robust phenomenon. Moreover, our results showed that depressed mood reduced memory enhancement related to the survival judgment task. These results supported the combination hypothesis which explained the benefits of survival judgment tasks (Nouchi, 2011a,b). The combination hypotheses assumed that elaboration process would be important to elicit the memory enhancement of the survival judgment task. The survival judgment tasks would facilitate to conduct elaboration processes. Therefore, memory performance of the survival judgment task was higher than memory performance of other encoding tasks regardless of depressed mood. However, a degree of elaboration in depressed participants was lower than that in nondepressed participants (Breslow et al., 1981; Derry and Kuiper, 1981; Weingartner et al., 1981, 1982; Kuiper and Derry, 1982). Thus, the memory enhancement of the survival judgment tasks in depressed participants was lower compared to non-depressed participants. Our findings may suggest that elaboration processing would be a key concept to understand the mechanism of the memory enhancement of the survival judgment task. 


\section{ACKNOWLEDGMENTS}

This study was supported by a Grant-in-Aid for Japan Society for the Promotion of Science (JSPS) Fellows (grant no.235019; http://www.jsps.go.jp/english/e-pd/index.html). The funders had

\section{REFERENCES}

Anderson, J. R., and Reder, L. M. (1979). "An elaborative processing explanation of depth of processing," in Levels of Processing in Human Memory, eds L. S. Cermak and F. I. M. Craik (Hillsdale, NJ: Erlbaum), 385-403.

Austin, M. P., Mitchell, P., and Goodwin, G. M. (2001). Cognitive deficits in depression: possible implications for functional neuropathology. $\mathrm{Br}$. J. Psychiatry 178, 200-206.

Beck, A. T., and Beamesderfer, A. (1974). Assessment of depression: the depression inventory. Mod. Probl. Pharmacopsychiatry 7, 151-169.

Blaney, P. H. (1986). Affect and memory: a review. Psychol. Bull. 99, 229-246.

Bower, G. H. (1981). Mood and memory. Am. Psychol. 36, 129-148.

Bradley, B. P., and Mathews, A. (1988). Memory bias in recovered clinical depressives. Cogn. Emot. 2, 235-245.

Brantley, P. J., Mehan, D. J., and Thomas, J. L. (2000). "The Beck Depression Inventory (BDI) and the Centre for Epidemiologic Studies Depression Scale (CES-D)," in Handbook of Psychological Assessment in Primary Care Settings, ed. M. E. Maruish (Mahwah, NJ: Erlbaum), 391-421.

Breslow, R., Kocsis, J., and Belkin, B. (1981). Contribution of the depressive perspective to memory function in depression. Am. J. Psychiatry 138, 227-230.

Burt, D. B., Zembar, M. J., and Niederehe, G. (1995). Depression and memory impairment: a metaanalysis of the association, its pattern, and specificity. Psychol. Bull. 117, 285-305.

Butler, A. C., Kang, S. H. K., and Roediger, H. L. (2009). Congruity effects between materials and processing tasks in the survival processing paradigm. J. Exp. Psychol. Learn. Mem. Cogn. 35, 1477-1486.

Craik, F. I. M., and Lockhart, R. (1972). Levels of processing: A framework for memory research. J. Verb. Learn. Verb. Behav. 11, 671-684.

Craik, F. I. M., and Tulving, E. (1975). Depth of processing and the retention of words in episodic memory. J. Exp. Psychol. Gen. 104, 268-294.

Daselaar, S. M., Veltman, D. J., Rombouts, S. A. R. B., Raaijmakers, J. G. W., and Jonker, C. (2003).
Deep processing activates the medial temporal lobe in young but not in old adults. Neurobiol. Aging 24, 1005-1011.

Derry, P. A., and Kuiper, N. A. (1981). Schematic processing and self-reference in clinical depression. J. Abnorm. Psychol. 90, 286-297.

Ellis, H. C., and Ashbrook, P. W. (1988). "Resource allocation model of the effects of depressed mood states on memory," in Affect, Cognition, and Social Behavior, eds K. Fiedler and J. Forgas (Goettingen: Hogrefe), 25-43.

Ellis, H. C., Ottaway, S. A., Varner, L. J., Becker, A. S., and Moore, B. A. (1997). Emotion, motivation, and text comprehension: the detection of contradictions in passages. J. Exp. Psychol. Gen. 126, 131-146.

Erber, J., Herman, T. G., and Botwinick, J. (1980). Age differences in memory as a function of depth of processing. Exp. Aging Res. 6, 341-348. in incidental learning. Dev. Psychol. 10, 936-941.

Fossati, P., Coyette, F., Ergis, A.-M., and Allilaire, J.-F. (2002). Influence of age and executive functioning on verbal memory of inpatients with depression. J. Affect. Disord. 68, 261-271.

Gagne, E. (1985). The Cognitive Psychology of School Learning. Boston, MA: Little, Brown and Company.

Hertel, P. T. (1994). Depressive deficits in word identification and recall. Cogn. Emot. 8, 313-327.

Hertel, P. T. (1998). Relation between rumination and impaired memory in dysphoric moods. J. Abnorm. Psychol. 107, 166-172.

Hertel, P. T., and Hardin, T. S. (1990). Remembering with and without awareness in a depressed mood: evidence of deficits in initiative. J. Exp. Psychol. Gen. 119, 45-59.

Hertel, P. T., and Rude, S. S. (1991). Depressive deficits in memory: Focusing attention improve subsequent recall. J. Exp. Psychol. Gen. 120, 301-309.

Ilsley, J. E., Moffoot, A. P., and O'Carroll, R. E. (1995). An analysis of memory dysfunction in major depression. $J$. Affect. Disord. 35, 1-9.

Jacob, F. (1977). Evolution and tinkering. Science 196, 1161-1166.

Kang, S. H. K., McDermott, K. B., and Cohen, S. M. (2008). The mnemonic advantage of processing
Eysenck, M. W. (1974). Age differences

no role in study design, data collection and analysis, decision to publish, or preparation of the manuscript. We thank the participants and all colleagues in the IDAC, Tohoku University for their support.

fitness-relevant information. Mem. Cognit. 36, 1151-1156.

Kendall, P. C., Hollon, S. D., Beck, A. T., Hammen, C. L., and Ingram, R. E. (1987). Issues and recommendations regarding use of the Beck Depression Inventory. Cognit. Ther. Res. 11, 289-299

Klein, S. B., Cosmides, L., Tooby, J., and Chance, S. (2002). Decisions and the evolution of memory: multiple systems, multiple functions. Psychol. Rev. 109, 306-329.

Klein, S. B., and Kihlstrom, J. F. (1986). Elaboration, organization, and the self-reference effect in memory. $J$. Exp. Psychol. Gen. 115, 26-38.

Kojima, M., Furukawa, T. A., Takahashi, H., Kawai, M., Nagaya, T., and Tokudome, S. (2002). Cross-cultural validation of the Beck Depression Inventory-II in Japan. Psychiatry Res. 110, 291-299.

Kroneisen, M., and Erdfelder, E. (2011) On the plasticity of the survival processing effect. J. Exp. Psychol. Learn. Mem. Cogn. 37, 1553-1562.

Kuiper, N. A., and Derry, P. A. (1982). Depressed and nondepressed content self-reference in mild depressives. J. Pers. 50, 67-80.

LaBar, K. S., and Cabeza, R. (2006). Cognitive neuroscience of emotional memory. Nat. Rev. Neurosci. 7, 54-64.

Matsuoka, K., Uno, M., Kasai, K. Koyama, K., and Kim, Y. (2006). Estimation of premorbid IQ in individuals with Alzheimer's disease using Japanese ideographic script (Kanji) compound words: Japanese version of National Adult Reading Test. Psychiatry Clin. Neurosci. 60, 332-339.

McDermott, L. M., and Ebmeier, K. P. (2009). A meta-analysis of depression severity and cognitive function. J. Affect. Disord. 119, 1-8.

Nairne, J. S. (2005). "The functionalist agenda in memory research," in Experimental Cognitive Psychology and its Applications: Festschrift in Honor of Lyle Bourne, Walter Kintsch, and Thomas Landauer, ed. A. F. Healy (Washington, DC: American Psychological Association), 115-126.

Nairne, J. S., and Pandeirada, J. N. S. (2008). Adaptive memory: is survival processing special? J. Mem. Lang. 59, 377-385.

Nairne, J. S., and Pandeirada, J. N. S. (2010). Adaptive memory: nature's criterion and the functionalist agenda. Am. J. Psychol. 123, 381-390.

Nairne, J. S., and Pandeirada, J. N. S. (2011). Congruity effects in the survival processing paradigm. J. Exp. Psychol. Learn. Mem. Cogn. 37, 539-549.

Nairne, J. S., Pandeirada, J. N. S., Gregory, K. J., and Van Arsdall, J. E. (2009). Adaptive memory: fitness relevance and the hunter-gatherer mind. Psychol. Sci. 20, 740-746.

Nairne, J. S., Pandeirada, J. N. S., and Thompson, S. R. (2008). Adaptive memory: The comparative value of survival processing. Psychol. Sci. 19, 176-180.

Nairne, J. S., Thompson, S. R., and Pandeirada, J. N. S. (2007). Adaptive memory: survival processing enhances retention. J. Exp. Psychol. Learn. Mem. Cogn. 33, 263-273.

Nouchi, R. (2011a). Individual differences of visual imagery ability in the benefit of a survival judgment task. Jpn. Psychol. Res. 53, 319-326.

Nouchi, R. (2011b). The effect of aging on memory enhancement related to the survival judgment task. Jpn. Psychol. Res. doi: 10.1111/j.14685884.2011.00483.x

Ogawa, T., and Inamura, T. (1974). An analysis of word attributes imagery, concreteness, meaningfulness and ease of learning for Japanese nouns. Shinrigaku Kenkyu 44, 317-327.

Otgaar, H., and Smeets, T. (2010) Adaptive memory: Survival processing increases both true and false memory in adults and children. $J$. Exp. Psychol. Learn. Mem. Cogn. 36, 1010-1016.

Otgaar, H., Smeets, T., and van Bergen, S. (2010). Picturing survival memories: enhanced memory after fitnessrelevant processing occurs for verbal and visual stimuli. Mem. Cognit. 38, 23-28.

Ramel, W., Goldin, P. R., Eyler, L. T., Brown, G. G., Gotlib, I. H., and McQuaid, J. R. (2007). Amygdala reactivity and mood-congruent memory in individuals at risk for depressive relapse. Biol. Psychiatry 61, 231-239.

Ramponi, C., Murphy, F. C., Calder, A. J., and Barnard, P. J. (2010). Recognition memory for pictorial material in subclinical depression. Acta Psychol. (Amst) 135, 293-301. 
Ramponi, C., Nayagam, J. S., and Barnard, P. J. (2009). Conceptual implicit memory in subclinical depression. Cogn. Emot. 23, 551-568.

Rogers, T. B., Kuiper, N. A., and Kirker, W. S. (1977). Self-reference and the encoding of personal information. J. Pers. Soc. Psychol. 35, 677-688.

Sheline, Y. I., Barch, D. M., Garcia, K., Gersing, K., Pieper, C., WelshBohmer, K., Steffens, D. C., and Doraiswamy, P. M. (2006). Cognitive function in late life depression: relationships to depression severity, cerebrovascular risk factors and processing speed. Biol. Psychiatry 60, 58-65.

Soderstrom, N. C., and McCabe, D. P. (2011). Are survival processing memory advantages based on ancestral priorities? Psychon. Bull. Rev. 18, 564-569.
Tooby, J., and Cosmides, L. (1992). “The psychological foundations of culture," in The Adapted Mind: Evolutionary Theory and the Generation of Culture, ed. D. Buss (New York: Oxford Press), 19-136.

Tooby, J., and Cosmides, L. (2005) "Conceptual foundations of evolutionary psychology," in The Handbook of Evolutionary Psychology, ed. D. Buss (Hoboken, NJ: Wiley), 5-67.

Veiel, H. O. (1997). A preliminary profile of neuropsychological deficits associated with major depression. J. Clin. Exp. Neuropsychol. 19, 587-603.

Weingartner, H., Cohen, R. M., Bunney, W. E., Ebert, M. H., and Kaye, W. (1982). Memory-learning impairments in progressive dementia and depression. Am. J. Psychiatry 139, 135-136.

Weingartner, H., Cohen, R. M., Murphy, D. L., Martello, J., and Gerdt,
C. (1981). Cognitive processes in depression. Arch. Gen. Psychiatry 38, 42-47.

Weinstein, Y., Bugg, J. M., and Roediger, H. L. (2008). Can the survival recall advantage be explained by basic memory processes? Mem. Cognit. 36, 913-919.

Williams, J. M., Barnhofer, T., Crane, C. Herman, D., Raes, F., Watkins, E., and Dalgleish, T. (2007). Autobiographical memory specificity and emotional disorder. Psychol. Bull. 133, 122-148.

Williams, J. M. G., Watts, F. N. MacLeod, C. M., and Andrew, M. (1997). Cognitive Psychology and Emotional Disorders, 2nd Edn. Chichester: Wiley.

Conflict of Interest Statement: The authors declare that the research was conducted in the absence of any commercial or financial relationships that could be construed as a potential conflict of interest.

Received: 29 December 2011; accepted: 30 March 2012; published online: 18 Apri 2012.

Citation: Nouchi $R$ and Kawashima $R$ (2012) Effect of the survival judgment task on memory performance in subclinically depressed people. Front. Psychology 3:114. doi: 10.3389/fpsyg.2012.00114

This article was submitted to Frontiers in Cognitive Science, a specialty of Frontiers in Psychology.

Copyright (C) 2012 Nouchi and Kawashima. This is an open-access article distributed under the terms of the Creative Commons Attribution Non Commercial License, which permits non-commercial use, distribution, and reproduction in other forums, provided the original authors and source are credited. 


\section{APPENDIX}

Table A1 | Stimuli used for our experiment.

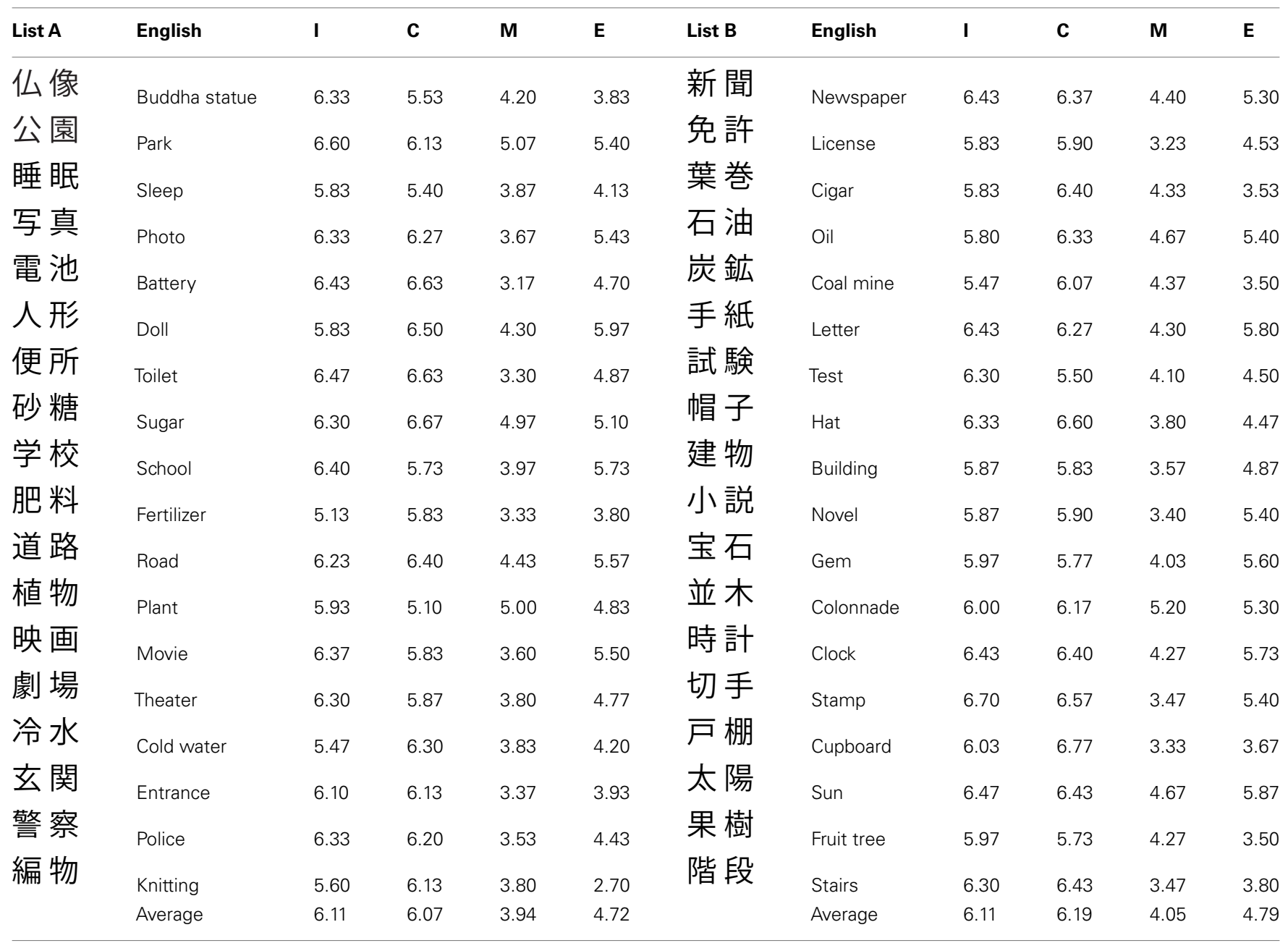

I, imagery; $C$, concreteness; $M$, meaningfulness; $E$, ease of learning. 